\title{
THE MEAN CONSISTENCY OF THE WEIGHTED ESTIMATOR IN THE FIXED DESIGN REGRESSION MODELS BASED ON $m$-END ERRORS
}

\author{
Weifeng Xu, Yi Wu, Rui Zhang, Huiling Jiang And Xuejun Wang
}

Abstract. In this paper, some moment inequalities for $m$-extended negatively dependent $(m$ END, for short) random variables are established which can be applied to investigate the nonparametric regression models based on $m$-END errors. Some results on mean consistency for the estimator in nonparametric regression models are presented. As an application, the consistency for the nearest neighbor estimator is obtained.

Mathematics subject classification (2010): 62G05.

Keywords and phrases: $m$-extended negatively dependent random variables, fixed design regression models, mean consistency, nearest neighbor estimator.

\section{REFERENCES}

[1] P. Y. Chen, P. BAI, S. H. SUng, The von Bahr-Esseen moment inequality for pairwise independent random variables and applications, Journal of Mathematical Analysis and Applications 419 (2), 12901302, 2014.

[2] Y. Chen, A. Chen, K. W. NG, The strong law of large numbers for extend negatively dependent random variables, Journal of Applied Probability 47, 908-922, 2010.

[3] A. A. GEORGIEV, Local properties of function fitting estimates with applications to system identification, in: W. Grossmann et al. (Eds.). Mathematical Statistics and Applications, Volume B, Proceedings 4th Pannonian Symposium on Mathematical Statistics, 4-10, September, 1983, Bad Tatzmannsdorf, Austria, Reidel, Dordrecht, 141-151, 1985.

[4] A. A. Georgiev, Consistent nonparametric multiple regression: The fixed design case, Journal of Multivariate Analysis 25 (1), 100-110, 1988.

[5] A. A. GeORgIEv, W. GReBLICKI, Nonparametric function recovering from noisy observations, Journal of Statistical Planning and Inference 13, 1-14, 1986.

[6] S. H. HU, G. M. PAN, Q. B. GAO, Estimate problem of regression model with linear process errors, Applied Mathematics: A Journal of Chinese Universities 18 (1), 81-90, 2003.

[7] H. Y. LiAng, B. Y. JING, Asymptotic properties for estimates of nonparametric regression models based on negatively associated sequences, Journal of Multivariate Analysis 95 (2), 227-245, 2005.

[8] L. Liu, Precise large deviations for dependent random variables with heavy tails, Statistics and Probability Letters 79 (9), 1290-1298, 2009.

[9] L. LIU, Necessary and sufficient conditions for moderate deviations of dependent random variables with heavy tails, Science in China Series A: Mathematics 53 (6), 1421-1434, 2010.

[10] H. G. MÜLLER, Weak and universal consistency of moving weighted averages, Periodica Mathematica Hungarica 18 (3), 241-250, 1987.

[11] D. H. Qiu, P. Y. Chen, R. G. ANTONini, A. Volodin, On the complete convergence for arrays of rowwise extended negatively dependent random variables, Journal of the Korean Mathematical Society 50 (2), 379-392, 2013.

[12] G. G. RousS AS, Consistent regression estimation with fixed design points under dependence conditions, Statistics and Probability Letters 8, 41-50, 1989.

[13] G. G. Roussas, L. T. TRAn, D. A. IOANnides, Fixed design regression for time series: Asymptotic normality, Journal of Multivariate Analysis 40 (2), 262-291, 1992. 
[14] A. T. SHEN, Probability inequalities for END sequence and their applications, Journal of Inequalities and Applications, vol. 2011, Article ID 98, 12 pages, 2011.

[15] A. T. SHEN, Bernstein-type inequality for widely dependent sequence and its application to nonparametric regression models, Abstract and Applied Analysis, vol. 2013, Article ID 862602, 9 pages, 2013.

[16] A. T. SHEN, On asymptotic approximation of inverse moments for a class of nonnegative random variables, Statistics: A Journal of Theoretical and Applied Statistics 48 (6), 1371-1379, 2014.

[17] A. T. SHEN, Complete convergence for weighted sums of END random variables and its application to nonparametric regression models, Journal of Nonparametric Statistics 28 (4), 702-715, 2016.

[18] A. T. Shen, Y. Zhang, A. Volodin, Applications of the Rosenthal-type inequality for negatively superadditive dependent random variables, Metrika 78 (3), 295-311, 2015.

[19] L. Tran, G. Roussas, S. Yakowitz, B. T. VAn, Fixed-design regression for linear time series, The Annals of Statistics 24 (3), 975-991, 1996.

[20] X. J. WAng, S. J. WAng, S. H. Hu, J. M. Ling, Y. F. WeI, On complete convergence of weighted sums for arrays of rowwise extended negatively dependent random variables, Stochastics: An International Journal of Probability and Stochastic Processes 85 (6), 1060-1072, 2013.

[21] X. J. WANG, Y. WU, S. H. HU, Exponential probability inequality for $m$-END random variables and its applications, Metrika 79 (2), 127-147, 2016.

[22] Y. F. Wu, M. GuAN, Convergence properties of the partial sums for sequences of end random variables, Journal of the Korean Mathematical Society 49 (6), 1097-1110, 2012.

[23] Y. F. WU, M. C. ORdoneZ, A. Volodin, Complete convergence and complete moment convergence for arrays of rowwise end random variables, Glasnik Matematički 49 (69), 449-468, 2014.

[24] W. Z. YANG, X. J. WANG, X. H. WANG, et al., The consistency for estimator of nonparametric regression model based on NOD errors, Journal of Inequalities and Applications, vol. 2012, Article ID 140, 13 pages, 2012.

[25] W. Z. YANG, H. Y. XU, L. Chen, S. H. HU, Complete consistency of estimators for regression models based on extended negatively dependent errors, Statistical Papers, doi:10.1007/s00362-016-0771-x, in press, 2016. 